\title{
Acceptability of an intelligent wireless sensor system for the rapid detection of health issues: findings among home-dwelling older adults and their informal caregivers
}

\author{
This article was published in the following Dove Press journal: \\ Patient Preference and Adherence \\ 6 September 2016 \\ Number of times this article has been viewed
}

\section{Christine Cohen \\ Thomas Kampel \\ Henk Verloo}

Department Ra\&D, La Source School of Nursing Sciences, University of Applied Sciences and Arts Western Switzerland, Lausanne, Switzerland
Correspondence: Christine Cohen Department Ra\&D, La Source School of Nursing Sciences, University of Applied Sciences and Arts Western Switzerland, 30 Avenue Vinet, $\mathrm{CH}$ - 1004 Lausanne, Switzerland

Tel $+4|2|$ 64I 3867

Fax +4I 2I 64I 3810

Email c.cohen@ecolelasource.ch
Background: Aging at home rather than in an institution is now considered the gold standard. Public health figures document an important demographic transition to an increasingly elderly society. At the same time, this is accompanied by the emergence of significant numbers of innovative technologies to help and support home-dwelling older adults in declining health who wish to remain at home.

Study aim: To explore the acceptability of intelligent wireless sensor system (IWSS) among home-dwelling older adults in rapidly detecting their health issues.

Methods: Data were sourced from a pilot 3-month randomized clinical trial that involved 34 older patients in the experimental group (EG) using an IWSS to rapidly detect falls and other health issues at home. The effectiveness of the IWSS was assessed by comparing it to participants' functional and cognitive status, as measured both before and after the trial. The Resident Assessment Instrument for Home Care, Confusion Assessment Method, Cognitive Performance Scale, Geriatric Depression Scale, and Informed Questionnaire on Cognitive Decline in the Elderly were used for the assessments. Acceptability of the IWSS was explored at the end of the study.

Results: Both older adults and their informal caregivers considered the performance and usefulness of the IWSS intervention to be low to moderate. A majority of the participants were unsatisfied with its ease of use and found multiple obstacles in using and having an intention to use the IWSS. However, their informal caregivers were more satisfied with the program and gave higher scores for usefulness, ease of use, and intention to use IWSS technology.

Conclusion: The IWSS displayed low-to-moderate acceptability among the older participants and their informal caregivers. We recommend improving and clarifying several components in the IWSS for the development of a design that is user-centered.

Keywords: gerontechnology, satisfaction, patient preferences, home monitoring, elderly care, informal caregiver preferences, innovative technology

\section{Introduction}

The Swiss population is aging, with higher absolute numbers of adults aged 65 years old and above. By 2020, about 1.2 million older adults will be living in Switzerland. ${ }^{1}$ The majority of the home-dwelling older adults wish to live in their own homes for as long as possible, even when they need significant health care. ${ }^{2}$ Extremely rapid, innovative technological development is occurring in parallel to this demographic transformation. ${ }^{3}$ However, although most technological devices are aimed at young adults, recent 
studies have provided evidence that older age groups can adopt and use innovative technology as well. ${ }^{4-6}$ This has led to growing interest in technologies to enable older people to live autonomously at home. These gerontechnologies should help home-dwelling older adults to remain safely in their homes for longer, despite physical and cognitive decline. ${ }^{7,8}$ This emerging concept combines technologies to improve health, housing, mobility, and communication in order to prevent social isolation and loneliness in older people. Moreover, it increases home-dwelling older adults' safety at home, monitors their health status to reinforce their independence and quality of life, and enables them to remain at home longer, even if they have some neurocognitive impairment. ${ }^{9,10}$ Health status among the sustained home-dwelling adults was monitored using well-documented and validated tools. Literature documents that most global assessments to detect behavior changes were made with the Resident Assessment Instrument for Home Care (RAI-HC ${ }^{\circledR}$; InterRAI Coporation, Washington, DC, USA), ${ }^{11}$ cognitive status with the Confusion Assessment Method (CAM) ${ }^{12}$ Cognitive Performance Scale (CPS), ${ }^{13}$ Geriatric Depression Scale (GDS), ${ }^{14}$ and Informant Questionnaire on Cognitive Decline in the Elderly. ${ }^{15}$ However, regular health status assessments by home health care nurses for rapid detection of changes in health status among home-dwelling older adults remain difficult.

Most patients prefer care in the community to more expensive care in nursing homes; therefore, systems using advanced technology to meet that preference should benefit older patients, health care providers, and public health policymakers. ${ }^{16-18}$ Health care providers, engineers, and public health policymakers are exploring this alternative method of services that aim to maintain older adults in declining health at home and improve their quality of life. ${ }^{19,20}$ Based on the continuity theory of normal aging, which proposes that older adults make adaptive choices to preserve and maintain internal and external networks with family and friends, ${ }^{21}$ gerontechnology should help an aging society maintain sustainability by helping older adults enjoy a better quality of life and increasing their autonomy. ${ }^{22}$ Although there have been some preliminary evidences about the positive impact of gerontechnology on health outcomes and quality of life, resulting in home-dwelling older adults remaining autonomous longer, few studies have focused on their acceptance of these emerging technologies. ${ }^{23-25}$ However, research should better document how acceptable, usable, and intrusive that technology can be. Finally, it is important to understand the factors that influence the acceptance and use of innovative technologies in the daily lives of home-dwelling older adults in declining health. This article describes the acceptability of an innovative intelligent wireless sensor system (IWSS) for rapidly detecting health issues among home-dwelling older adults in declining health. This pilot 3-month randomized clinical trial was carried out in collaboration with a district home health care service in southwestern Switzerland. For research guidance, this project adopted the technological acceptance model framework developed by Venkatesh and Davis in $2012 .^{26}$

\section{Theoretical framework}

Technology acceptance has been described as "the approval, favorable reception, and ongoing use of newly introduced devices and systems". ${ }^{5}$ The level of acceptance contains an element of the attitude toward a certain behavior changed by the technology, that is, the individual's positive or negative feeling or appraisal about that behavior and the degree to which this affects the behavior, and the technology-use behavior itself. The unified theory of acceptance and use of technology framework developed by Venkatesh and Davis ${ }^{26}$ was used as a framework to investigate home-dwelling older adults' acceptance of the IWSS. Based on theories from psychology and sociology, the unified theory of acceptance and use of technology 2 was developed to better understand what influences the behavioral intentions to use technology. ${ }^{27}$

\section{Study aims}

This study aimed to explore the acceptability (usefulness, satisfaction, ease of use, and intention to use) of an IWSS among home-dwelling older adults. This innovative technology rapidly detects everyday health issues such as falls, acute infections, and immobilization, with the aim of preventing hospitalization or emergency department visits.

\section{Materials and methods Study design}

Data were sourced from a pilot randomized clinical trial conducted from August 1, 2014, to the end of March 2015. The trial used an IWSS to rapidly detect health issues among older adults receiving home health care. In addition to the effectiveness of the IWSS, the study explored its acceptability among home-dwelling older adults and their informal caregivers.

\section{Setting and participants}

The study nurse (SN), in partnership with a district home health care service in the French-speaking part of Canton Valais, Switzerland, recruited 34 older patients receiving 
home health care. The study was approved by the Canton's human research ethics committee in June 2014 (CCVEM 020/14). Participation in the study was voluntary; homedwelling older adults in declining health who were asked to participate were under no obligation to do so. Older patients with a medical prescription for home health care, independent of their degree of physical or cognitive impairment, were eligible to participate if they met the following criteria: 1) aged 65 years or above; 2) had received at least 3 months of home health care without interruption during the length of the IWSS trial; 3) independent despite their degree of physical and cognitive impairment; and 4) capable of understanding and answering questions in French. The exclusion criteria were: 1) they were at the end of life; 2) they had received lesser than 3 months of home health care in one go; and 3) they were incapable of answering questions in French (language barrier).

\section{Sample, recruitment, and blinding}

The principal investigator (PI) and the $\mathrm{SN}$ attempted to recruit 99 participants, of whom 68 gave their written informed consent and were assigned, using opaque sealed envelopes, to either the experimental group (EG; $n=34)$ or the control group (CG; $n=34)$. A total of 57 participants completed the study: 29 in the EG and 28 in the CG groups. The PI, SN, and district home health care service were aware of the group allocations because of the technological interventions which needed to be prepared for and adapted to the participants in the EG. Participants in the EG received the IWSS intervention in addition to the planned "usual care" intervention from the district home health care center. Participants in the CG received only the identical planned "usual care".

\section{IWSS intervention}

Prior to the intervention, the IWSS, study protocol, and the management of alarms were explained to the participants, informal caregivers, and nurses. Nurses received a short training session on how to use the IWSS software. Participants in the EG received their IWSS within 72 hours of getting the explanation. Prior to the 3-month clinical trial with the IWSS, a 2-week assessment period evaluated the participants' normal patterns of behavior. Alarm thresholds for use during the clinical trial were chosen by the Homecare Center in collaboration with the informal caregiver.

The IWSS intervention consisted of continuously recording the movements and activity/inactivity of the homedwelling older adults in strategic places in their living space: living room, bedroom, bathroom, time spent in bed, and time at which the fridge was opened.

The collected data were sent for analysis to the DomoSafety ${ }^{\circledR}$ data management center using mobile technologies. Based on the participants' 2-week behavior pattern before the trial, a data algorithm was able to analyze and detect changing behaviors ( $>20 \%$ deviation) among the home-dwelling older adults with declining health. Depending on the participants' changing behavior patterns (eg, more visits to the bathroom, falls, acute infection, shorter stays in bed), the system sends alarm messages to their contact informal caregivers, who can then access the IWSS smart application to discover the nature of the change in movement/activity (on a dashboard). Contacts can receive alarms by short message service, email, or smartphone application in a domino effect.

\section{Data collection}

Assessment of sociodemographic characteristics and health status

Immediately after obtaining consent, the PI and SN conducted a basic assessment of each participant by administering a number of different instruments in a face-to-face interview. These included the RAI-HC, ${ }^{11}$ the $\mathrm{CAM}^{12}$ for the symptoms/ signs of delirium, the CPS, ${ }^{13}$ the GDS-4 items, ${ }^{14}$ the Informant Questionnaire on Cognitive Decline in the Elderly, ${ }^{15}$ and medications. They also examined patient records to collect data on patients' sociodemographic characteristics (age, sex, marital status, living situations), prescribed medications, and global health status. Inter-rater reliability between the PI and $\mathrm{SN}$ was excellent with regards to the assessments made using the RAI-HC, CAM, CPS, and GDS (with Cohen's kappa coefficients between 0.79 and 0.85$){ }^{28}$

\section{Assessment of acceptability}

Data about acceptability were collected throughout the study. These were obtained from the personal notes written by the PI and SN, as well as from the results of the questionnaire. The questionnaires were administered during face-to-face or telephonic interviews with the participants after the IWSS was used for 3 months without interruption. ${ }^{29,30}$ In the absence of a validated questionnaire on the acceptability of the IWSS, a questionnaire was developed based on the scientific publications of Davis, ${ }^{31}$ Venkatesh et al, ${ }^{27}$ and Sidani and Braden (Figure S1). ${ }^{32}$ The questionnaire assessed the intervention's ease of use, usefulness, and attitudes and the intentions to use the IWSS. In addition, satisfaction with the physical installation procedure of the IWSS and the feelings of safety generated 
by the intervention were measured using a 5-point Likert scale scored from 0 "not acceptable/not at all satisfactory" to 4 "extremely acceptable/very satisfying". Two open-ended questions based on the critical incident technique ${ }^{33}$ allowed the participants to express their opinions and describe their positive and negative experiences of the IWSS. Finally, the participants were invited to make suggestions about the usefulness of IWSS and the information received about the IWSS.

\section{Data analysis}

Descriptive statistics were used to present sociodemographic and health status characteristics. The most appropriate statistical tests were selected according to the type of variables. Statistical analyses were performed using version 22 of the IBM-Statistical Package for Social Sciences (IBM-SPSS ${ }^{\circledR}$; IBM Corporation, Armonk, NY, USA). ${ }^{34}$ A statistical significance threshold value was established at $P=0.05$ and all tests were two tailed.

Qualitative data were summarized using content analysis. ${ }^{35,36}$ The information collected was processed as follows: 1) interview summaries were audio-recorded in a digital format; 2) the interviewer analyzed the interview content to identify positive, negative, or neutral events; and 3) critical incidents were identified, classified, and organized by theme. The hierarchical categorization procedure specific to the Flanagan method was used. ${ }^{33}$ During this classification into categories, the taxonomy of specific attitudes and the creation of new categories were developed continuously, as Flanagan proposed, so that all incidents were classified according to the specificities of the process and the participants involved.

\section{Findings}

We observed an elevated participant retention rate in both EG (29/34) and CG, suggesting that participants were interested in exploring the use of the IWSS. No statistical difference was observed in the attrition rates of the groups $(P \leq 0.05)$. Three deaths and two institutionalizations were the reasons for attrition.

\section{Sociodemographic characteristics}

Table 1 summarizes the sociodemographic characteristics of the participants receiving the IWSS intervention. Majority of the participants were female (67.6\%), aged over 83 years, and lived alone $(91.2 \%)$.

\section{Participants' health status}

As expected, the health status of these older participants at study entry revealed cognitive impairment, delirium, and symptoms of depression, as well as significant
Table I Sociodemographic characteristics of the EG participants

\begin{tabular}{|c|c|}
\hline Variables & Participants $(n=34)$ \\
\hline Age (years), mean (SD) & $83.2(7.2)$ \\
\hline \multicolumn{2}{|l|}{ Sex, n (\%) } \\
\hline Female & $23(67.6)$ \\
\hline \multicolumn{2}{|l|}{ Marital status, n (\%) } \\
\hline Unmarried & $5(14.7)$ \\
\hline Married/partner & I (2.9) \\
\hline Divorced/separated & $3(8.9)$ \\
\hline Widowed & $24(70.6)$ \\
\hline Missing & I (2.9) \\
\hline \multicolumn{2}{|l|}{ Cohabitation, n (\%) } \\
\hline Lives alone & $3 \mid(9 \mid .2)$ \\
\hline With spouse & $3(8.8)$ \\
\hline \multicolumn{2}{|l|}{ Dwelling place, $n$ (\%) } \\
\hline Own home with nursing homecare & $33(97.1)$ \\
\hline Serviced apartment & I (2.9) \\
\hline \multicolumn{2}{|l|}{ Additional support services, n (\%) } \\
\hline Homecare assistant & $27(79.4)$ \\
\hline Home cleaning & $28(82.3)$ \\
\hline Meals at home & $13(38.2)$ \\
\hline Volunteer & $4(\mathrm{II} .8)$ \\
\hline Social worker & $4(11.8)$ \\
\hline Occupational therapy or physiotherapist & $3(8.8)$ \\
\hline Day hospital & $4(11.8)$ \\
\hline
\end{tabular}

Abbreviations: EG, experimental group; SD, standard deviation.

polypharmacy, with an average of more than six drugs used daily (Table 2).

\section{Acceptability of the IWSS intervention}

Table 3 presents participants' answers to the acceptability questionnaire.

\section{Usefulness of IWSS}

More than half of the emergency alarm messages were sent out during the night, and participants in these situations often took an extended time to return to bed. Food burning on hotplates was another incident detected at two participants' homes and the IWSS sent emergency alarm messages to their nurses and informal caregivers. The IWSS failed to detect two falls, probably due to lack of suitably positioned sensors. Insufficient training for nurses on the use of IWSS caused several difficulties in the effective employment of its software in the study. Participants living long distances from their informal caregivers showed more interest in using IWSS.

\section{Satisfaction}

Only 6/23 participants (26.1\%) were satisfied with the IWSS, while more than half of their informal caregivers were satisfied $(8 / 15 ; 53.3 \%)$. However, architectural complexity had caused the IWSS some problems in capturing every activity at homes. Two informal caregivers complained about the 
Table 2 Participants' health status

\begin{tabular}{|c|c|}
\hline Variables & Participants $(n=34)$ \\
\hline \multicolumn{2}{|c|}{ Confusion Assessment Method (CAM 9 items) } \\
\hline Mean number of symptoms (SD) & $1.9(1.5)$ \\
\hline$($ Min-max) & $0-5$ \\
\hline \multicolumn{2}{|l|}{ Cognitive Performance Scale (CPS) } \\
\hline Mean (SD) & $2.3(2.4)$ \\
\hline$(\operatorname{Min}-\max )$ & $0-10$ \\
\hline \multirow{2}{*}{\multicolumn{2}{|c|}{$\begin{array}{l}\text { Informant Questionnaire on Cognitive Decline } \\
\text { in the Elderly (IQCODE) }\end{array}$}} \\
\hline & \\
\hline Mean (SD) & $3.9(0.6)$ \\
\hline$($ Min-max) & $3.1-4.8$ \\
\hline \multicolumn{2}{|l|}{ Geriatric Depression Scale (GDS 4 items) } \\
\hline Mean (SD) & $0.9(I)$ \\
\hline$(\operatorname{Min}-\max )$ & $0-3$ \\
\hline RAI-HC: fell during the last 3 months (\%) & 50 \\
\hline Risk of falling (\%) & 94.1 \\
\hline \multicolumn{2}{|l|}{ RAI-HC: number of drugs } \\
\hline Mean (SD) & $8.8(4.2)$ \\
\hline$($ Min-max) & $0-18$ \\
\hline RAI-HC: social isolation/loneliness (\%) & 58.8 \\
\hline \multicolumn{2}{|l|}{ RAI-HC: pain-visual analog scale } \\
\hline No pain (\%) & 29.4 \\
\hline Mild pain (\%) & 32.4 \\
\hline Average pain (\%) & 38.2 \\
\hline \multicolumn{2}{|l|}{ RAI-HC: hospitalized in the last 3 months } \\
\hline Yes (\%)/no (\%) & $14.7 / 85.3$ \\
\hline
\end{tabular}

Abbreviations: max, maximum; min, minimum; RAl-HC, Resident Assessment Instrument for Home Care; SD, standard deviation.

long time necessary to install the wireless sensors. One participant estimated that a single sensor was inappropriate for capturing every activity.

Acceptability of IWSS in the daily lives of participants and informal caregivers

Most of the participants (15/23; 65.2\%) and informal caregivers $(13 / 18 ; 72.2 \%)$ considered the IWSS installation procedure acceptable. For more than half of the participants (52.2\%), IWSS had no negative influences on their activities of daily living. Informal caregivers were dissatisfied with the need to acknowledge each alarm message with a telephone call to assess the pertinence of the alarm and whether any physical intervention was necessary. Participants also felt that the IWSS was intrusive and that they were being watched. In a few families, these situations even went so far as to create conflicts between participants and their relations. Half of the informal caregivers (53.9\%) stated that the alarm messages influenced their daily lives, and some of them, for professional reasons, were not always reachable. Furthermore, some rural areas were not always covered by the mobile phone network and some alarm messages did not reach the informal caregivers. For these reasons, one-fifth of the participants or informal caregivers contemplated leaving the study.

\section{Use of IWSS}

About one-fifth (21.7\%) of the participants and half (53.3\%) of the informal caregivers were satisfied with the use of IWSS. Regarding the usefulness of IWSS, one-third (34.8\%) of the participants and three-quarters (76.5\%) of the informal caregivers considered the IWSS useful for older adults who wished to remain in their homes, and believed that the IWSS was an appropriate means of ensuring safety in case of falls.

Only one-third $(33.8 \%)$ of the alarm messages were described as useful; however, only one-fifth of the messages $(20 \%)$ were described as actually requiring further investigation (by telephone call). One-third of the alarm messages (33.5\%) were described as not useful, and almost one-sixth of the messages $(13.8 \%)$ had technical errors.

\section{Ease of use and obstacles to the IWSS}

During the clinical follow-up, patients stated that short distances from informal caregivers, their declining health status,

Table 3 Acceptability questionnaire

\begin{tabular}{|c|c|c|c|c|}
\hline \multirow[t]{2}{*}{ Questions } & \multicolumn{2}{|c|}{ Participants, n (\%) } & \multicolumn{2}{|c|}{$\begin{array}{l}\text { Informal } \\
\text { caregivers, n (\%) }\end{array}$} \\
\hline & Yes & No & Yes & No \\
\hline Compared to what was presented to you, are you satisfied with the use of the IWSS? & $6(26.1)$ & $17(73.9)$ & $8(53.3)$ & $7(46.7)$ \\
\hline Was the IWSS useful? & $5(21.7)$ & $18(78.3)$ & $8(53.3)$ & $7(46.7)$ \\
\hline Do you feel that the IWSS became essential to your daily living? & $3(13.6)$ & $19(83.4)$ & $6(37.5)$ & $10(62.5)$ \\
\hline Did the installation of the IWSS cause any trouble? & $15(65.2)$ & $8(34.8)$ & $13(72.2)$ & $5(27.8)$ \\
\hline Was the use of the IWSS easy? & $10(45.5)$ & $12(54.5)$ & $12(80)$ & $3(20)$ \\
\hline Is the IWSS a good system for ensuring the safety of older adults at home? & $8(34.8)$ & $15(65.2)$ & $13(76.5)$ & $4(23.5)$ \\
\hline Did the IWSS disturb your daily living? & II (47.8) & $12(52.2)$ & $6(46.2)$ & $7(53.8)$ \\
\hline Would you recommend the IWSS to a home-dwelling older adult? & $8(34.8)$ & $15(65.8)$ & $13(76.5)$ & $4(23.5)$ \\
\hline Did you hesitate to participate in the study? & $8(36.4)$ & $14(63.6)$ & $5(27.8)$ & $13(72.2)$ \\
\hline Did you ever think about withdrawing from the study before it was finished? & $5(22.7)$ & $17(77.3)$ & $3(16.7)$ & $15(83.3)$ \\
\hline
\end{tabular}

Abbreviation: IWSS, intelligent wireless sensor system. 
and fear of falls or being found dead by family members made the IWSS worth using and encouraged them to do so. Participants and informal caregivers who stated that they had received clear, understandable information at the IWSS also felt that this facilitated the system's use.

Participants' ease of use was negatively influenced by mild or moderate cognitive impairment, resulting in a need for supplementary explanations about the IWSS. For several reasons, informal caregivers were mostly absent during the installation of the system and while giving explanations about the IWSS, resulting in inappropriate responses to emergency alarm messages. Finally, obstacles to the system's ease of use were also due to some of its components such as the failing mobile telephone connections in rural areas, which required the health care nurses to make adjustments and reduced the system's usefulness.

\section{Discussion}

The present study showed that the IWSS programs installed were not always easy to use and generally demonstrated only low-to-moderate acceptability. Despite the reasons which most participants and their informal caregivers gave to remain at home as long as possible, the IWSS failed to precisely and rapidly detect every health issue in daily life. This resulted in the IWSS only achieving a moderate score for usefulness, as revealed by one informal caregiver's statement: "The sensors are an interesting concept, but they are not yet intelligent enough to quickly detect the first signs of changing health symptoms or tell us that something really serious has happened." The IWSS intervention was also meant to focus on preventing avoidable hospitalizations and help participants remain in their homes; on these measures, the system's functionality failed to meet the participants' expectations. Results showed that the IWSS generated several inappropriate preventive messages. During the study, emergency messages transferred to informal caregivers alone failed to result in appropriate, well-organized follow-up. It does not seem to be relevant to connect informal caregivers to the IWSS and expect them to be available to respond, day or night, to both appropriate and inappropriate sensor alarm messages. This both exhausted informal caregivers and developed a flawed feeling of safety among the participants surrounded by sensors.

In agreement with previous studies, the present study confirmed that older adults with a cognitive impairment were less likely to accept the IWSS than those with a physical impairment. ${ }^{37}$ Moreover, the biggest complaints from participants were about the IWSS intervention's intrusiveness and complexity, which corroborated other studies. ${ }^{38-40}$ This tends to support the possible explanation that older adults suffering from a cognitive impairment find innovative technologies too complicated to use, and thus, the interventions are not always useful in helping them to become more independent or offering them the benefits of an enhanced quality of life. Also, the IWSS demonstrated multiple unexpected technical failures, which caused feelings of doubt about its ease of use and applicability for increasing autonomy at home and enhancing the quality of life. However, if the participant and informal caregiver had received a suitably comprehensible explanation and the IWSS had provided useful outcomes, then this would probably have resulted in the higher acceptability documented in other studies. ${ }^{39}$ It is probable that these barriers negatively influenced informal caregivers' scores for satisfaction with and usefulness of this innovative technology for maintaining older adults in declining health in their homes; this corroborates the recent study by Gibson et al. ${ }^{41}$

Finally, families that refused to support or continue to participate in the study may have feared losing family privacy, disclosing family conflicts, or overintrusive assessments; these findings were also documented by Hastall et al. ${ }^{42}$ Innovative technologies spark society's interest and curiosity, but can also reveal fears that should be addressed with the potential users.

The present study recommends that innovative technology developed by engineers should use a differentiated targeting strategy to assess the specific needs of home-dwelling older adults, as differences in usage intentions were related to participants' sociodemographic and health status characteristics. More importantly, the study revealed that older adults' attitudes toward innovative technologies are significant determinants of their usage intentions; their positive and negative attitudes lead to higher and lower usage intentions, respectively. Thus, technologies should be developed in close collaboration with the end-users. Such a user-centered approach could improve their attitudes toward innovative technologies and is likely to yield more fruitful outcomes.

\section{Study limitations}

This study has some limitations concerning the acceptability of the intervention and the study itself. In addition to the relatively small sample, it seems important to mention that data were collected by a single district home health care center and that attention should be drawn to the transferability of our findings. Extending our findings to other technologies or regions should be done with caution. Finally, our study population of older adults was particularly unfamiliar with innovative technologies due to their average age of about 
83 and the transferability of our findings to older adults less than 75 years old should be done with caution.

\section{Conclusion}

Gerontechnologies have been developed independently of the needs of potential users. This study demonstrated that sufficient time should be taken to understand the habits, perceptions, and preferences of home-dwelling older adults and their informal caregivers before trying to encourage the adoption of new technologies. Indeed, they expressed only a low to moderate acceptability of the IWSS intervention. This result should be considered a challenge to engineers and technology developers; they should collaborate more closely with end-users and clinical researchers in order to investigate the acceptability of different types of innovative technology. Their overriding goal should remain to keep older adults in their own homes and in optimal physical and mental health for as long as possible.

\section{Acknowledgments}

We thank the patients and their families for their participation in this study. This work would not have been possible without the participation of the nurses of the district home health care centers in Valais. The authors also thank Prof D Gatica-Perez (IDEAP), ME Goupy (DomoSafety), and MG DuPasquier (DomoSafety) for their contribution to the IWSS intervention. This study was funded in part by Switzerland's Commission for Technology and Innovation (Innovation Promotion Agency). The sponsors played no role in the design and conduct of the study, data collection, management, analysis, or interpretation of the data; nor in the preparation, review, or approval of the manuscript.

\section{Author contributions}

All authors contributed to fundraising, study concept, data acquisition, analysis, and interpretation, statistical analysis, manuscript drafting and revision, gave final approval of the version to be published, and agree to be accountable for all aspects of the work.

\section{Disclosure}

The authors report no conflicts of interest in this work.

\section{References}

1. Office Fédéral de la Statistique. Encyclopédie statistique de la Suisse [Swiss statistical encyclopedia 2015]. Neuchâtel, Switzerland: Office Fédéral de la Statistique; 2015. French.

2. Höpflinger F, Hugentobler V. Les besoins en soins des personnes âgées en Suisse: Prévisions et scénarios pour le 21ème siècle [Healthcare needs of older adults in Switzerland: prevision and scenarios for the 21th century]. Neuchâtel: Observatoire de la santé; 2011. French.
3. Blaschke CM, Freddolino PP, MullenEE. Ageing and technology: a review of the research literature. Br J Soc Work. 2009;39(4):641-656.

4. Marziali E. Gerontechnology: research and practice in technology and aging. $C J A / R C V .2006 ; 25(2): 237-238$.

5. Arning K, Ziefle M. Understanding age differences in PDA acceptance and performance. Comput Hum Behav. 2007;23(6):2904-2927.

6. Cutler SJ. Ageism and technology. Generations. 2005;29(3):67-72.

7. Gangbé M, Ducharme F. Le "bien-vieillir": concepts et modèles ["Healthy Aging": concepts and models]. Méd Sci. 2006;22(3):297-300. French.

8. Rice T. Assistive technology: new ways to promote independence. Nurs Res Care. 2003;5(9):440-441.

9. Cohen-Mansfield J, Biddison J. The scope and future trends of gerontechnology: consumers' opinions and literature survey. J Technol Human Ser. 2007;25(3):1-19.

10. Pilotto A, D’Onofrio G, Benelli E, et al. Information and communication technology systems to improve quality of life and safety of Alzheimer's disease patients: a multicenter international survey. J Alzheimers Dis. 2011;23(1):131-141.

11. Anliker M, Bartelt G, Du Pasquier J-N, et al. Manuel RAI-Home-Care Suisse - Manuel d'application de la méthode RAI-Home-Care Suisse pour les services à domicile en Suisse [RAI Home-care Manual: application of the RAI-Home care method to the Swiss home healthcare services. Version 2.0]. Version 2.0. St Gallen: Q-Sys AG; 2009. French.

12. Inouye SK, Vandyck CH, Siegal AP, Horwitz RI. Clarifying confusiona new screening method for identifying acute confusional state. Clin Res. 1989;37(2):A314.

13. Morris JN, Fries BE, Mehr DR, et al. Mds Cognitive Performance Scale(C). J Gerontol. 1994;49(4):M174-M182.

14. Yesavage JA, Brink TL, Rose TL, et al. Development and validation of a geriatric depression screening scale: a preliminary report. J Psychiatr Res. 1982;17(1):37-49.

15. Jorm AF. A Short-form of the Informant Questionnaire on cognitive decline in the elderly (Iqcode) - development and cross-validation. Psychol Med. 1994;24(1):145-153.

16. Miskelly FG. Assistive technology in elderly care. Age Ageing. 2001; 30(6):455-458.

17. Mann WC. The potential of technology to ease the care provider's burden. Generations. 2001;25(1):44-48.

18. Shenk D, Kuwahara K, Zablotsky D. Older women's attachments to their home and possessions. J Aging Stud. 2004;18(2):157-169.

19. Tinker A. Assistive technology and its role in housing policies for older people. Qual Ageing. 2003;4(2):4-12.

20. Scharlach A, Graham C, Lehning A. The "village" model: a consumer-driven approach for aging in place. Gerontologist. 2012;52(3): 418-427.

21. Lang FR, Rohr MK. Successful aging in western societies: the 'selection, optimization, and compensation' model. In: Wright JD, editor. International Encyclopedia of the Social \& Behavioral Sciences. 2nd ed. Oxford: Elsevier; 2015:667-672.

22. Bronswijk JEMHV, Bouma H, Fozard JL. Technology for quality of life: an enriched taxonomy. Gerontechnology. 2003;2(2):169-172.

23. Beswick AD, Gooberman-Hill R, Smith A, Wylde V, Ebrahim S. Maintaining independence in older people. Rev Clin Gerontol. 2010;20(2): $128-153$.

24. Fozard JL, Rietsema J, Bouma H, Graafmans JAM. Gerontechnology: Creating enabling environments for the challenges and opportunities of aging. Edu Gerontol. 2000;26(4):331-344.

25. Lim WM, Pei-Lee T, Ahmed PK, Chan AHS, Soon-Nyean C, Wen-Jiun Y. Are older adults really that different? Some insights from gerontechnology. Paper presented at: Industrial Engineering and Engineering Management (IEEM), 2015 IEEE International Conference on; December 6-9; 2015.

26. Venkatesh V, Davis FD. A Theoretical extension of the technology acceptance model: four longitudinal field studies. Manage Sci. 2000; 46(2):186-204. 
27. Venkatesh V, Thong JYL, Xu X. Consumer acceptance and use of information technology: extending the unified theory of acceptance and use of technology. MIS Quart. 2012;36(1):157-178.

28. Hair JKJ, Black WC, Babin BJ, Anderson RE. Multivariate Data Analysis: a Global Perspective. 7th ed. Upper Saddle River, NJ: Pearson Education Inc; 2010.

29. Feeley N, Cossette S, Côté J, et al. The importance of piloting an RCT intervention. Can J Nurs Res. 2009;41(2):84-99.

30. Conn VS, Algase DL, Rawl SM, Zerwic JJ, Wyman JF. Publishing pilot intervention work. Western J Nurs Res. 2010;32(8):994-1010.

31. Davis FD, Bagozzi RP, Warshaw PR. User acceptance of computer technology: A comparison of two theoritical models. Management Science. 1989;35(8):982-1003.

32. Sidani S, Braden CJ. Design, Evaluation, and Translation of Nursing interventions. Oxford, UK: Wiley-Blackwell; 2011.

33. Flanagan J. The critical incident technique. Psychol Bull. 1954;51(4): 327-358.

34. IBM-SPSS. Statistical Package for Social Sciences Somer. Armonk, NY: IBM Corporation; 2011.

35. Burla L, Knierim B, Barth J, Liewald C, Duetz M, Abel A. From text to codings: intercoder reliability assessment in qualitative content analysis. Nurs Res. 2008;57(2):113-117.

36. Waltz CF, Strickland OL, Lenz ER. Measurement in Nursing and Health Research 4th ed. New York: Springer Publishing Company; 2010.
37. Kosse NM, Brands K, Bauer JM, Hortobagyi T, Lamoth CJC. Sensor technologies aiming at fall prevention in institutionalized old adults: a synthesis of current knowledge. Int J Med Inform. 2013;82(9): 743-752.

38. Mitseva A, Peterson CB, Karamberi C, et al. Gerontechnology: providing a helping hand when caring for cognitively impaired older adults-intermediate results from a controlled study on the satisfaction and acceptance of informal caregivers. Curr Gerontol Geriatr Res. 2012;2012:401705.

39. Burrow S, Brooks D. Atdementia: An information resource on assistive technologies that help support the independence of people with dementia. Dementia-London. 2012;11(4):553-557.

40. Brittain H, Corner L, Robinson L, Bond J. Ageing in place and technologies of place: the lived experience of people with dementia in changing social, physical and technological environments. Sociol Health Illn. 2010;32(2):272-287.

41. Gibson G, Dickinson C, Brittain K, Robinson L. The everyday use of assistive technology by people with dementia and their family carers: a qualitative study. BMC Geriatr. 2015;15(1):89.

42. Hastall MR, Eiermann ND, Ritterfeld U. Formal and informal carers' views on ICT in dementia care: Insights from two qualitative studies. Gerontechnology. 2014;13(1):51-56. 


\section{Supplementary material}

Family name - given name:

Date:

Acceptability is taken to mean effective acceptance of the DomoCare ${ }^{\circledR}$ sensor array by the study's participants - older adults and their informal caregivers.

\begin{tabular}{|c|c|c|c|c|c|}
\hline \multirow[t]{2}{*}{ Activity } & \multicolumn{5}{|c|}{ Acceptability score } \\
\hline & 0 & 1 & 2 & 3 & 4 \\
\hline \multicolumn{6}{|l|}{ Satisfaction with the DomoCare ${ }^{\circledR}$ sensor system } \\
\hline \multicolumn{6}{|l|}{$\begin{array}{l}\text { 1. Compared to what was presented to you, are you satisfied with the } \\
\text { use of the DomoCare }{ }^{\circledR} \text { sensor system? }\end{array}$} \\
\hline \multicolumn{6}{|l|}{$\begin{array}{l}\text { 2. How would you evaluate the usefulness of DomoCare }{ }^{\circledR} \text { sensor } \\
\text { system? (Did it help you, and if yes, in what way?) }\end{array}$} \\
\hline \multicolumn{6}{|l|}{$\begin{array}{l}\text { 3. In your opinion, did the DomoCare }{ }^{\circledast} \text { sensor system become an } \\
\text { indispensable part of your daily life? }\end{array}$} \\
\hline \multicolumn{6}{|l|}{ Installation of the DomoCare ${ }^{\circledR}$ sensor system } \\
\hline \multicolumn{6}{|l|}{$\begin{array}{l}\text { 4. Was the length of the assessment period prior to the installation of the } \\
\text { DomoCare }{ }^{\circledR} \text { sensor system acceptable? }\end{array}$} \\
\hline \multicolumn{6}{|l|}{ 5. Was the content of the interviews acceptable? } \\
\hline \multicolumn{6}{|l|}{ Adhesion - loyalty } \\
\hline \multicolumn{6}{|l|}{ 6. Did you hesitate about participating in this study? } \\
\hline \multicolumn{6}{|l|}{ 7. Did you contemplate withdrawing from the trial before it finished? } \\
\hline \multicolumn{6}{|l|}{ Credibility - usability - safety } \\
\hline \multicolumn{6}{|l|}{$\begin{array}{l}\text { 8. How would you describe the level of difficulty in getting the DomoCare }{ }^{\circledR} \\
\text { sensor system up and running? (older adult and/or informal carer) }\end{array}$} \\
\hline \multicolumn{6}{|l|}{ 9. Is the DomoCare ${ }^{\circledR}$ sensor system easy to use? } \\
\hline \multicolumn{6}{|l|}{$\begin{array}{l}\text { 10. Is the DomoCare }{ }^{\circledR} \text { sensor system a good way to ensure the safety of } \\
\text { home-dwelling older adults? }\end{array}$} \\
\hline \multicolumn{6}{|l|}{$\begin{array}{l}\text { 11. How would you describe the DomoCare }{ }^{\circledR} \text { sensor system's level of } \\
\text { disruption to your activities of daily living? }\end{array}$} \\
\hline $\begin{array}{l}\text { 12. Would you recommend the DomoCare }{ }^{\circledR} \text { sensor system to a home- } \\
\text { dwelling older adult? }\end{array}$ & & & & & \\
\hline
\end{tabular}

\section{Acceptability score}

$0=$ not acceptable/not at all satisfactory; $1=$ somewhat acceptable/somewhat satisfactory; $2=$ acceptable/satisfactory; $3=$ very acceptable/ more than satisfactory; $4=$ extremely acceptable/very satisfying.

Open-ended questions

Did you feel that the sensor system was useful to you? If so, how?

Did you have any difficulties with the DomoCare ${ }^{\circledR}$ sensor system during the trial?

\section{Propositions}

Figure SI Evaluation of the acceptability of the intelligent wireless sensor system.

\section{Reference}

1. Sidani S, Braden CJ. Design, Evaluation, and Translation of Nursing interventions. Oxford, UK: Wiley-Blackwell; 2011.

\section{Publish your work in this journal}

Patient Preference and Adherence is an international, peer-reviewed, open access journal that focuses on the growing importance of patient preference and adherence throughout the therapeutic continuum. Patient satisfaction, acceptability, quality of life, compliance, persistence and their role in developing new therapeutic modalities and compounds to optimize

\section{Dovepress}

clinical outcomes for existing disease states are major areas of interest for the journal. This journal has been accepted for indexing on PubMed Central. The manuscript management system is completely online and includes a very quick and fair peer-review system, which is all easy to use. Visit http://www. dovepress.com/testimonials.php to read real quotes from published authors. 